\title{
CORRECTION
}

\section{Correction to: Untreated incomplete isolated cleft palate: cadaveric findings}

\author{
Shogo Kikuta ${ }^{1,3}$ (1) $\cdot$ Joe Iwanaga ${ }^{1,2,3} \cdot$ Jingo Kusukawa ${ }^{3} \cdot$ Rod J. Oskouian $^{4} \cdot$ R. Shane Tubbs ${ }^{1,5}$
}

Published online: 12 March 2019

(C) Japanese Association of Anatomists 2019

\section{Erratum to:}

Anatomical Science International (2019) 94:154-157

https://doi.org/10.1007/s12565-018-00471-1

In the original publication, the given name and family name of the last author was incorrectly published. The correct given name and family name should be "R. Shane" and "Tubbs".

The online version of the original article can be found under https://doi.org/10.1007/s12565-018-00471-1

Publisher's Note Springer Nature remains neutral with regard to jurisdictional claims in published maps and institutional affiliations.

The original article can be found online at https://doi.org/10.1007/ s12565-018-00471-1.

Shogo Kikuta

kikuta.shougo4405@gmail.com

1 Seattle Science Foundation, 550 17th Avenue, Suite 600, Seattle, WA 98122, USA

2 Division of Gross and Clinical Anatomy, Department of Anatomy, Kurume University School of Medicine, Kurume, Fukuoka, Japan

3 Dental and Oral Medical Center, Kurume University School of Medicine, Kurume, Fukuoka, Japan

4 Swedish Neuroscience Institute, Swedish Medical Center, Seattle, WA, USA

5 Department of Anatomical Sciences, St. George's University, St. George's, West Indies, Grenada 